\title{
THE DETERMINATION OF THE DIREGTION OF MOVEMENT ON GLACIER SURFACES BY TERRESTRIAL PHOTOGRAMMETRY
}

\author{
B) Ulrigh Voigt
}

(Nationalkomitee für Geodäsie und Geophysik der Deutschen Demokratischen Republik bei der Deutschen Akademie der Wissenschaften, Berlin, Germany (D.D.R.))

\begin{abstract}
In order to determine longitudinal profiles of movement on glacier surfaces from photogrammetric surveys, it is necessary to know the direction of movement. The present method requires at least two base lines with overlapping ranges of photographs. The establishment of a base-line system for a given glacier form depends on the demands of accuracy. The method is applied to the movement of the glacier Kongsvegen (Vestspitsbergen) and the accuracy obtained is discussed. The movement direction of the points on the medial moraine of Kongsvegen does not coincide with the moraine direction.
\end{abstract}

RÉsumé. La détermination de la direction du mouvement superficiel des glaciers à l'aide de la photogrammétrie terrestre. La connaissance de la direction du mouvement est nécessaire notamment pour la détermination de profils de mouvement longitudinaux sur les surfaces de glaciers à partir de levés photogrammétriques. Pour la méthode exposée dans le travail présent, on a besoin d'au moins deux bases, dont les limites de la prise de vue se recouvrent. L'établissement d'un système de bases pour une forme donnée de glacier dépend des exigences de la précision. La méthode est appliquée au mouvement du Kongsvegen (Vestspitsberg) et la précision obtenue est discutée. La direction du mouvement des points de la moraine médiane du Kongsvegen ne coïncide pas avec celle de la moraine.

Zusammenfassung. Die Bestimmung der Bewegungsrichtung auf Gletscheroberflächen mittels terrestrischer Photogrammetrie. Besonders zur Bestimmung von longitudinalen Bewegungsprofilen auf Gletscheroberflächen aus photogrammetrischen Aufnahmen ist die Kenntnis der Bewegungsrichtung notwendig. Bei dem angegebenen Verfahren sind mindestens zwei Standlinien nötig, deren Aufnahmebereiche sich überdecken. Genauigkeitsforderungen bestimmen die Anlage eines Systems von Standlinien bei vorgegebener Gletscherform. Das Verfahren wird auf die Bewegung des Kongsvegen (Vestspitsbergen) angewendet und die erreichte Genauigkeit diskutiert. Die Bewegungsrichtung der Mittelmoränenpunkte des Kongsvegen fällt nicht mit der Moränenrichtung zusammen.

\section{INTRODUCTION}

Since its introduction by R. Finsterwalder ( 193 I) the terrestrial photogrammetric method of measuring the movement of glaciers has been widely used. In most cases the flow at the glacier surface is determined along several selected profiles which are nearly perpendicular to the valley axis and, consequently, to the assumed direction of movement (transverse profiles). Right at the beginning in the establishment of the base lines, care is taken that the bearing of the exposure axis is, as nearly as possible, perpendicular to the assumed direction of movement. In this case, the error resulting from small deviations of the true direction of flow from the assumed one is insignificant as long as the points to be measured are near the exposure axis. Sometimes it may be impossible in the field to establish base lines which fulfil these conditions.

In another method commonly used, viz. the evaluation of profiles in the direction of movement (longitudinal profiles), such an error may be several times as great as the absolute velocity in the margin of the picture. In order to determine longitudinal profiles, it is desirable to take several photographs in different directions from the same station the axes of which then form rather large angles with the direction of flow which, therefore, has to be known. The use of wide-angle lens cameras facilitates measurement of the movement over greater distances of selected profiles which, in the case of irregular glacier forms, are no longer perpendicular or parallel to the exposure axis and the direction of movement.

The ever increasing use of aerial photogrammetry provides direct determination of velocity vectors on glacier surfaces not only along selected lines but also across areas covered with point nets. The corresponding methods of terrestrial photogrammetry must be combined with the determination of the movement direction.

At the junction of several glacier branches, the change in the direction of movement is of 
major importance. Medial moraines are not always flow lines as impulse differences between the branches may lead to large lateral displacements of the moraines. From I 962 to I 964 , for example, the medial moraine of the glacier Kongsvegen (Vestspitsbergen) showed an average lateral displacement of $50 \mathrm{~cm}$. per day over a length of several kilometres whereas the forward movement was about $200 \mathrm{~cm}$./day. This corresponds to an angle of $\mathrm{I} 5{ }^{\circ}$ between the direction of the moraine and that of movement. This angle has not changed much up to 1965 .

All the reasons adduced here indicate the need for a practical method of determining the direction of movement.

The measurement of the vertical glacier displacements from photogrammetric models is a separate problem. Therefore the following discussion only deals with the two-dimensional movement in a horizontal plane.

A method for the determination of velocity vectors in areas covered with point nets (Rudolph and Töppler, unpublished) requires use of a stereoautograph and laboratory work. As a rule, it will be sufficient to know the direction of movement along selected profiles, and a stereocomparator will be the only instrument available for evaluation.

\section{Method}

A standard stereocomparator is used to measure parallaxes of movement in a horizontal direction perpendicular to the exposure axis. In order to obtain the true horizontal displacement of a point on the glacier surface from two components, it is necessary to have simultaneous pairs of pictures with time base from two different base lines both containing the point under consideration. The exposure axes may form any angle $\kappa$.

The displacement of a point, $\mathrm{P}$, is calculated from the pair of pictures of base $\mathrm{I}$ as the displacement, $V_{\mathrm{I}}$, perpendicular to the exposure axis, $y_{\mathrm{I}}$. At the same glacier point, the displacement, $V_{2}$, is obtained perpendicular to the direction $y_{2}$ from the pair of pictures of base 2. The vector of displacement $r$ cannot be derived by simple vector addition as the image is not provided by rays parallel to an orthogonal coordinate system but by rays passing through the centres of image (central perspective).

If the angle $\delta$ between the actual displacement $r$ and the positive abscissa $x$ is known, the actual horizontal displacement is determined (Fig. I) from

$$
r=\frac{V}{\cos \delta+\sin \delta \tan \phi^{\prime}}
$$

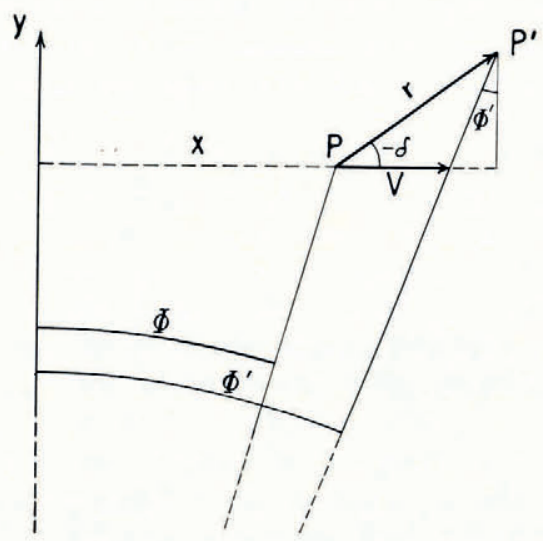

Fig. I. Diagram of the relation between the true and apparent movements of the point $\mathrm{P}$ 
where $\phi^{\prime}$ is the angle between the image ray to the end point $\mathrm{P}^{\prime}$ of the displacement and the ordinate $y$ given by

$$
\tan \phi^{\prime}=\tan \phi+\frac{V}{y}, \quad \tan \phi=\frac{x}{y} .
$$

As a rule, there is hardly any difference between $\tan \phi^{\prime}$ and $\tan \phi$ since $y$ is mostly very large as compared with $V$.

Let the angle between the exposure axes $y_{1}$ and $y_{2}$ be $\kappa$. From Figure 2 it follows that

$$
\kappa=\delta_{2}-\delta_{\mathrm{I}} \text {. }
$$

From the equations (I) written for the two systems of observation, one of the required angles $\delta$ can be eliminated. From equation (2) it follows that

$$
\tan \delta_{\mathrm{I}}=-\frac{\left(V_{2} / V_{\mathrm{I}}\right)-\cos \kappa-\sin \kappa \tan \phi_{2}}{\left(V_{2} \tan \phi_{\mathrm{I}}^{\prime} / V_{\mathrm{I}}\right)+\sin \kappa-\cos \kappa \tan \phi_{2}^{\prime}} .
$$

All the angles are to be inserted in counter-clockwise direction.

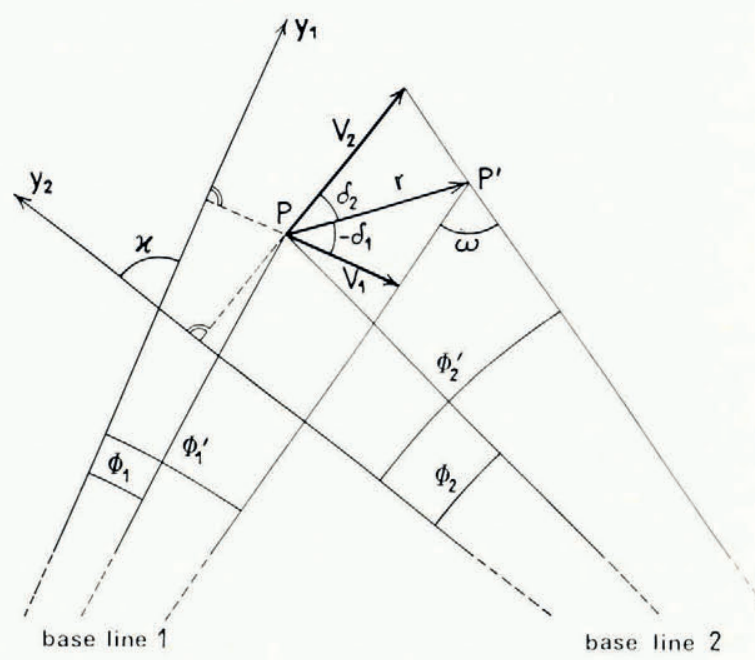

Fig. 2. Reconstruction of the displacement components determined from two photographs

For the special case of parallel axes of exposure and repeated exposures at the two end points of one base line, the introduction of picture coordinates leads to the formula given by Knizhnikov (1962).

It is rather difficult to locate identical glacier points on photographs taken from different base lines if only natural targets are available which are not easy to recognize. This problem may be solved by running longitudinal profiles along medial moraines. If such natural lines cannot be used, the profiles of one system of pictures must be converted to those of the other system. A small number of points is sufficient in order to measure the remaining profile correctly.

If there are more than two base lines with overlapping regions, it is necessary to transform the terrain coordinates into a uniform coordinate system. It would be better to use the system of state coordinates for this purpose. The selected point profiles are plotted at an appropriate scale. If the density of the points is sufficient, there are identical points on both photographs or the values of displacement of one pair of pictures are interpolated. 
The accuracy of the angles determined depends primarily on the size of the angle of intersection of the two image rays to the point $\mathrm{P}^{\prime}$. This angle is $\omega=\phi_{1}^{\prime}-\phi_{2}^{\prime}+\kappa$. For $\omega=\pi$ and $\omega=0$ the fraction in (3) is indefinite and the method fails. $\omega=\pi$ refers to the connecting line between the two repetition bases, $\omega=0$ refers to points at a very long distance relative to the length of this connecting line.

Because of the number and complexity of the steps of evaluation, the error of angle depends on further variables: the accuracy of the displacement measurements, along with the values of the angles $\kappa, \phi^{\prime}$ and $\delta$, affects the error in a complicated way. The case $\delta_{\mathrm{I}}=\pi / 2,3 \pi / 2$ with $\omega=\pi / 2,3 \pi / 2$, which is most favourable from a theoretical point of view, requires the combination of two exposures, one parallel to the direction of flow and the other perpendicular to it. In cases of intense local variations of the movement, it is especially important that the points are identical in both models. Where there are great velocity changes in time, greater significance must be attached to the simultaneity of the exposures, which also depends on the duration of the time interval.

The establishment of a system of base lines for the application of the method described can largely be planned in advance if the topography of the glacier and its surroundings is known. However, the final system of really practical bases will ultimately be modified more or less by the features of the terrain. In this connection, the following factors play a role: possibility of crossing the glacier, inclination of surface, form of slopes of the valley, as well as composition of field party and physical condition of its members, meteorological conditions and instrumentation. The usual establishment of base lines parallel to the glacier with normal photographs perpendicular to the assumed direction of flow is not always the best solution. The photographs parallel to the direction of flow which are especially suitable for the method can be taken on the mountain-ridge separating glacier branches which flow together.

\section{Application}

The system of base lines of the Deutsche Spitzbergen Expedition I $964 / 65$ at the glacier Kongsvegen (Fig. 3) was based on the experience gained during the Deutsche Spitzbergen Expedition 1962 (both expeditions were organized by the Nationalkomitee für Geodäsie und Geophysik der D.D.R. bei der Deutschen Akademie der Wissenschaften, Berlin) and is especially suitable for the application of the method developed by Rudolph and Töppler (unpublished). Of particular interest were the conditions of movement at the confluence of the two glaciers of Kronebreen and Kongsvegen and the distribution of the variations of movement in time along a longitudinal profile almost $15 \mathrm{~km}$. long. The movement survey has already been reported (Meier, r 965 ; Stange, r 965 ). Simultaneity of the photographs was achieved several times in an almost ideal form by using two field parties with two phototheodolites. The practical evaluation was carried out on a stereocomparator by the group passing the winter at Ny-Allesund (Kongsfjord); the method of Knizhnikov (1962) proved to be too inaccurate as the photograms contained only natural targets, such as crevasses, seracs, and moraine hills at normal base ratios. For this reason, the present method was devised and applied to the movement of Kongsvegen.

The medial moraines and the principal transverse profile measured previously several times (Voigt, I 965 ) were selected as profiles. From the extensive material (Io base lines with a total of $I_{74}$ repetitions, $6 I_{5}$ plates) intervals of $4,8, I_{6}, 3^{2}$ and 48 days for the determination of direction were chosen for the summer of 1964 . In general, multiple overlaps were used. The results are represented in Figure $4 . \delta_{0}$ is the angle between the computed direction of flow and north (west is $270^{\circ}$ ), distances are measured from the left bank of the glacier or along the medial moraine from its start at the foot of Garwoodtoppen.

For the principal transverse profile (Fig. 4a), a value of direction is obtained that is nearly constant over a glacier width of $2 \mathrm{~km}$. Three model combinations were used for the time 


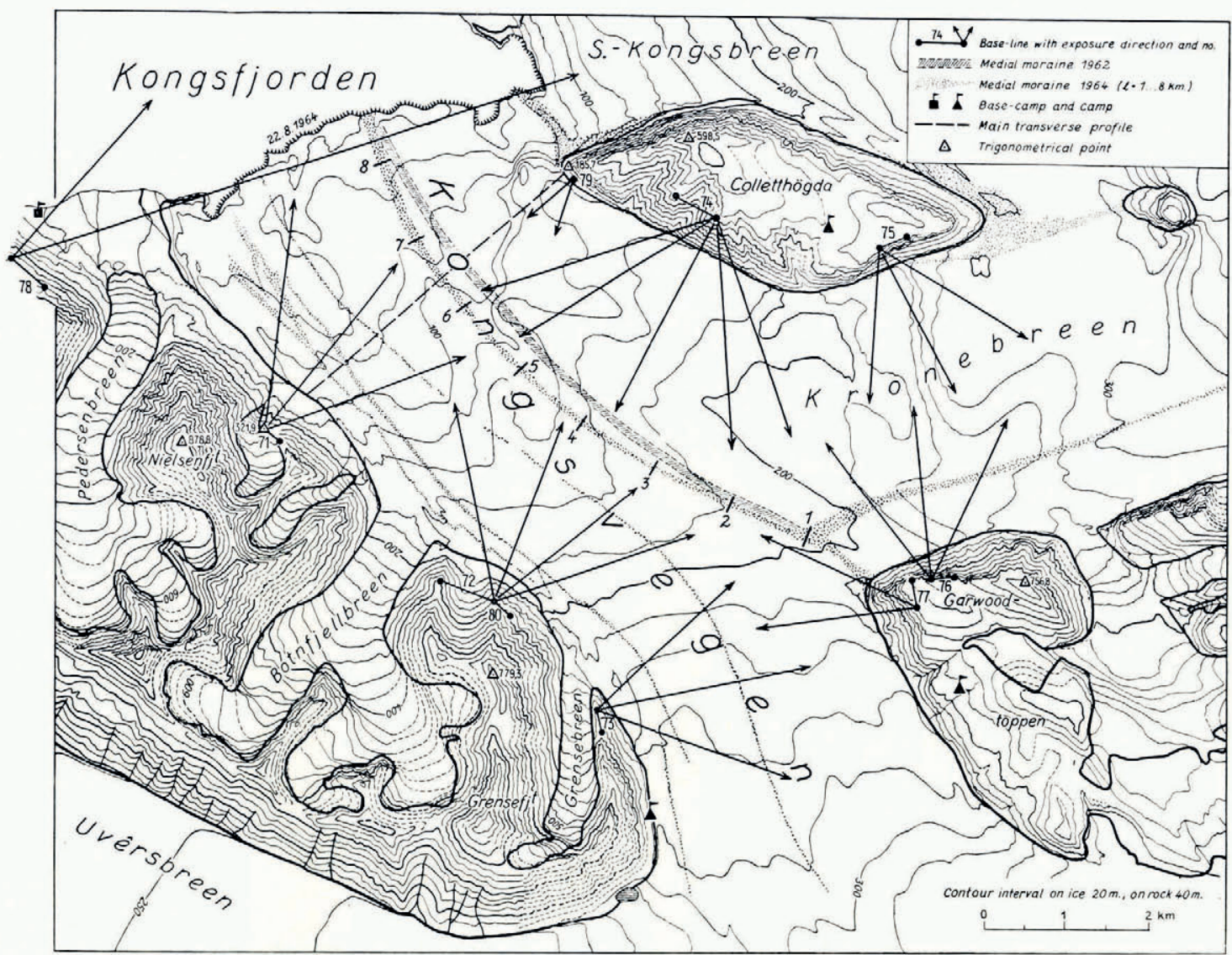

Fig. 3. Map of part of the glacier Kongsvegen showing photogrammetric base lines and exposure axes

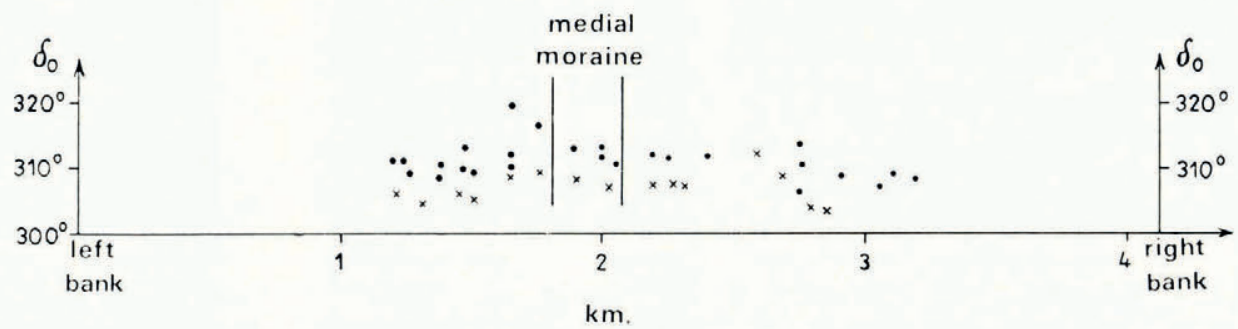

Fig. 4a. Direction of movement for points across the principal transverse profile. Circles mark points for the eight days $20-28$ August 1964 , crosses mark points for the four days 28 July-1 August 1964

interval of 8 days. The mean error of the angles is about $\pm \mathbf{2}^{\circ}$; the maximum deviation from the constant mean value is $\pm 6^{\circ}$ and it occurs if the angle of intersection $\omega$ is most unfavourable. For the previous interval of 4 days, from one combination, a smaller mean value is obtained at a mean deviation of $\pm 2^{\circ}$ and a maximum deviation of $\pm 3^{\circ}$. The glaciological cause of the reduced mean value will be discussed later. 
The experience gained in evaluation shows that the density of the glacier points should be especially high for profiles in which the same position has to be computed in the different models.

The movement direction along the medial moraine was determined over a length of $8 \mathrm{~km}$. from photographs of 8 base lines (1 2 directions) with a total of 22 model combinations for different time intervals (Fig. 4 b, c, d). Only such combinations were used in which the angle of intersection $\omega$ does not approach $\mathrm{I}^{\circ} \mathrm{o}^{\circ}$ within $\pm 20^{\circ}$. The photographs for the intervals of 4 and 8 days were taken simultaneously by two field parties, whereas for the other intervals corrections were applied to the values derived from less synchronous photographs.

The mean deviation of the direction values from an adjusting curve indicates that the error of the long-time and corrected values is larger. The interval of 16 days gives the largest

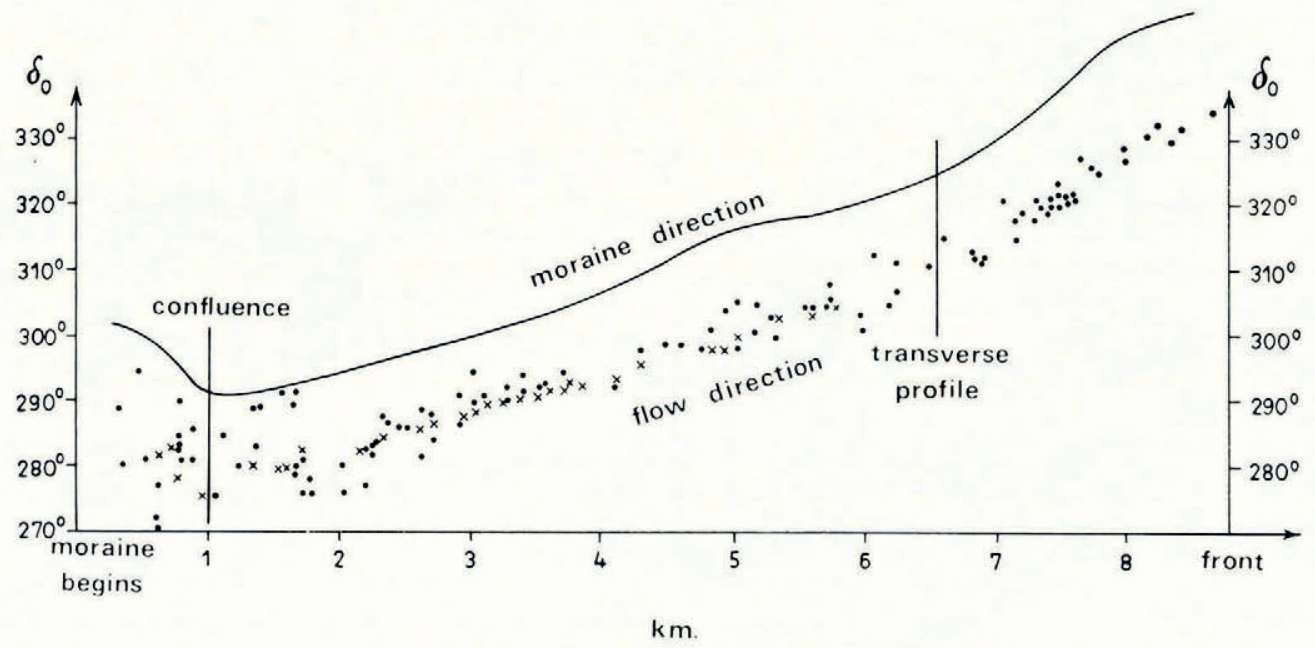

Fig. 4 b. Direction of movement down the longitudinal profile following the medial moraine. Points are plotted for periods of $I 6$ davs ( $1_{3}-28$ July), $3^{2}$ days (28 Fuly-28 August) and $4^{8}$ days (13 July-28 August 1964$)$

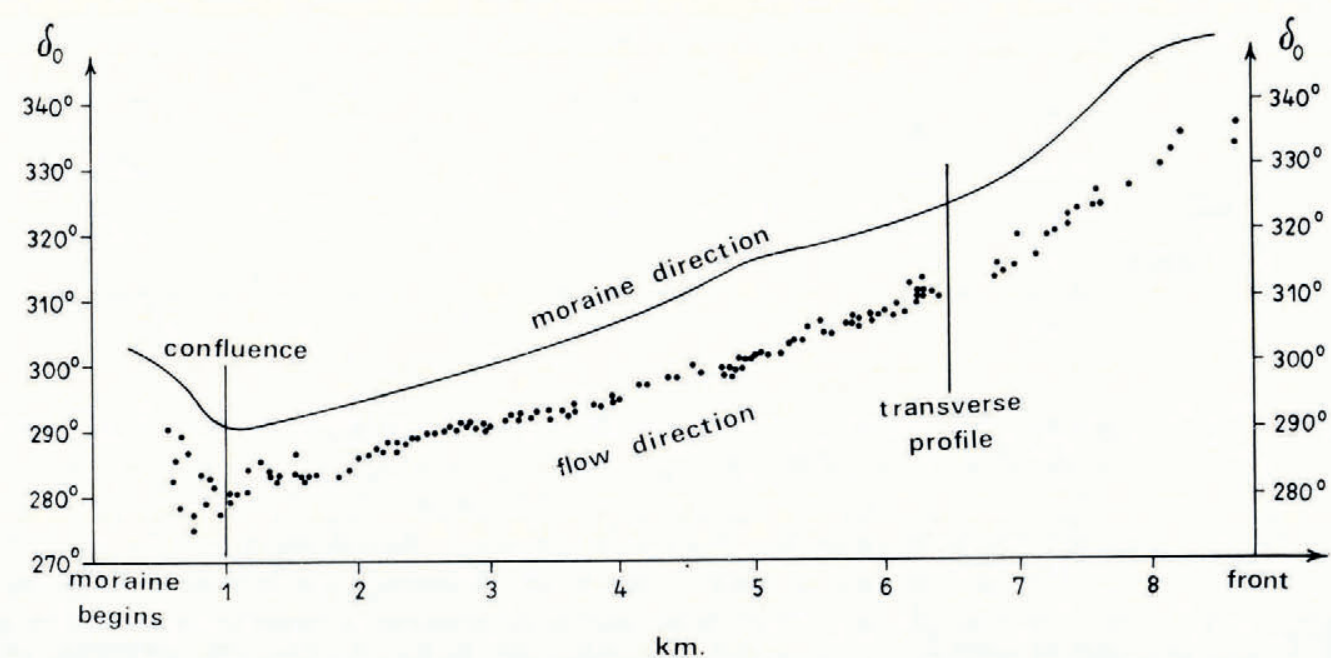

Fig. 4c. As Figure 4 b, but plotting points for the 8-day interval 20-28 August 1964 


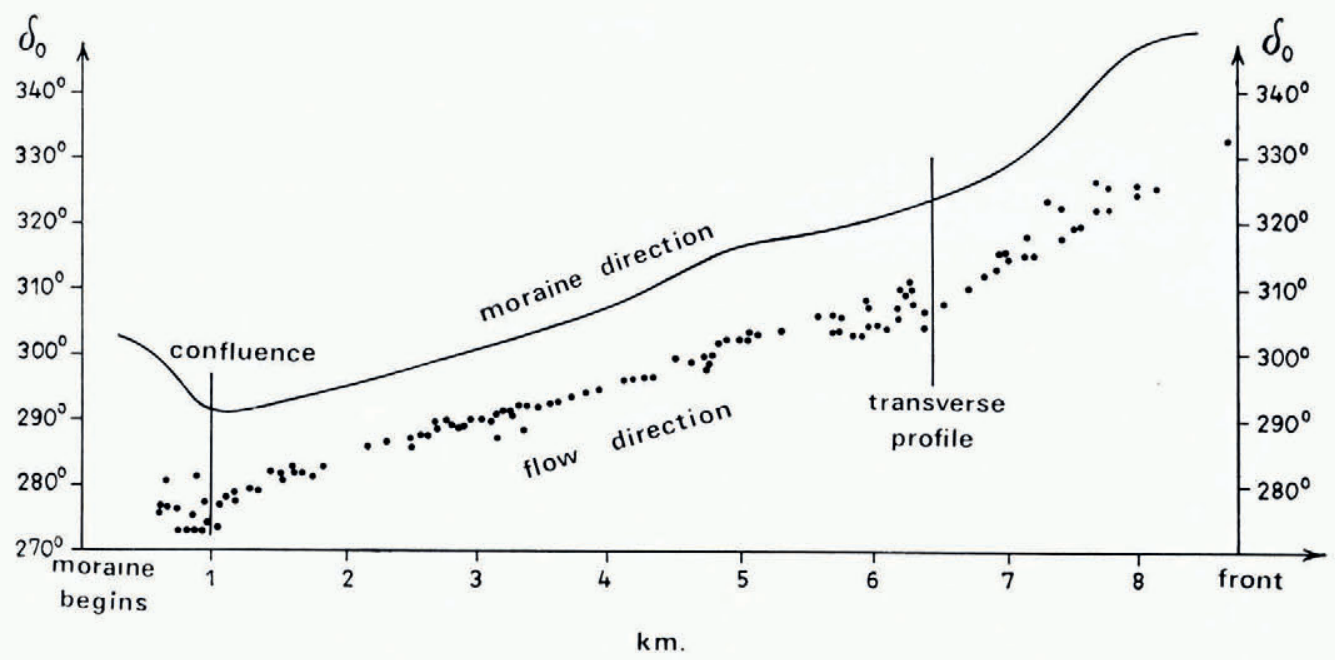

Fig. $4^{d}$. As Figure 4 , but plotting points for the 4 days 28 July-I August 1964

deviations as it falls in a period of intense movement variations in time (summer maximum). The same is true of the variations of the four-day interval as compared with those of the eight-day interval. Nevertheless, the differences of accuracy are small.

The angles $\delta_{1}$ and $\delta_{2}$ of the two base lines have the greatest influence on the deviation of the direction values from an adjusting curve. The ideal case $\delta_{\mathrm{I}}=3 \pi / 2=\omega$ is obtained with the photographs of base line 77 at Garwoodtoppen which are parallel to the direction of flow (Fig. 5). Although the relative error of displacement reaches a maximum because of the minimum displacements represented, these errors of the two photographs have hardly any effect. In Fig. $4 \mathrm{~b}$ the direction values which were derived from combinations with photographs of base line 77 , are identified by crosses forming a relatively smooth curve. In Figures $4 \mathrm{c}$ and $4 \mathrm{~d}$ the major part of the values for distances $l$ along the moraine up to $l=6 \cdot 5 \mathrm{~km}$. was deduced from combinations with these photographs. The mean deviation for this case is approx. $\pm 0.5^{\circ}$ whereas further down-glacier where the photographs of base 77 can no longer be used it is $\pm \mathrm{I} \cdot 5^{\circ}$. The maximum errors of direction in the longitudinal profile are $\pm 4^{\circ}$.

Special conditions produce a greater deviation along the first two kilometres: at $l=\mathrm{I} \mathrm{km}$. Kronebreen, which is distinguished by intense movement, flows laterally into Kongsvegen which may result in greater variations of direction. On the short section of the moraine above the confluence, the movements are so small that the displacement error in the two models has a greater effect.

Detailed direction determinations along the medial moraine of Kronebreen and in the confluence area are being evaluated. They provide the basis for the determination of the movement pattern for the case where glacier branches of different energy meet.

The following conclusions regarding glaciology are drawn from these results of direction determination. In the summer of 1964 the direction of flow is always outside the moraine direction. This means that there is a further shift of the medial moraine to the left which increases towards the front. As also the velocity increases up to $l=5 \mathrm{~km}$., the lateral displacement varies between ${ }_{1} 5 \mathrm{~cm}$./day and $50 \mathrm{~cm}$./day, a value that corresponds to that measured between 1962 and 1964 . The displacement of the medial moraine by about $2 \mathrm{~km}$. to the right which occurred in the early fifties simultaneously with a considerable advance of the front 


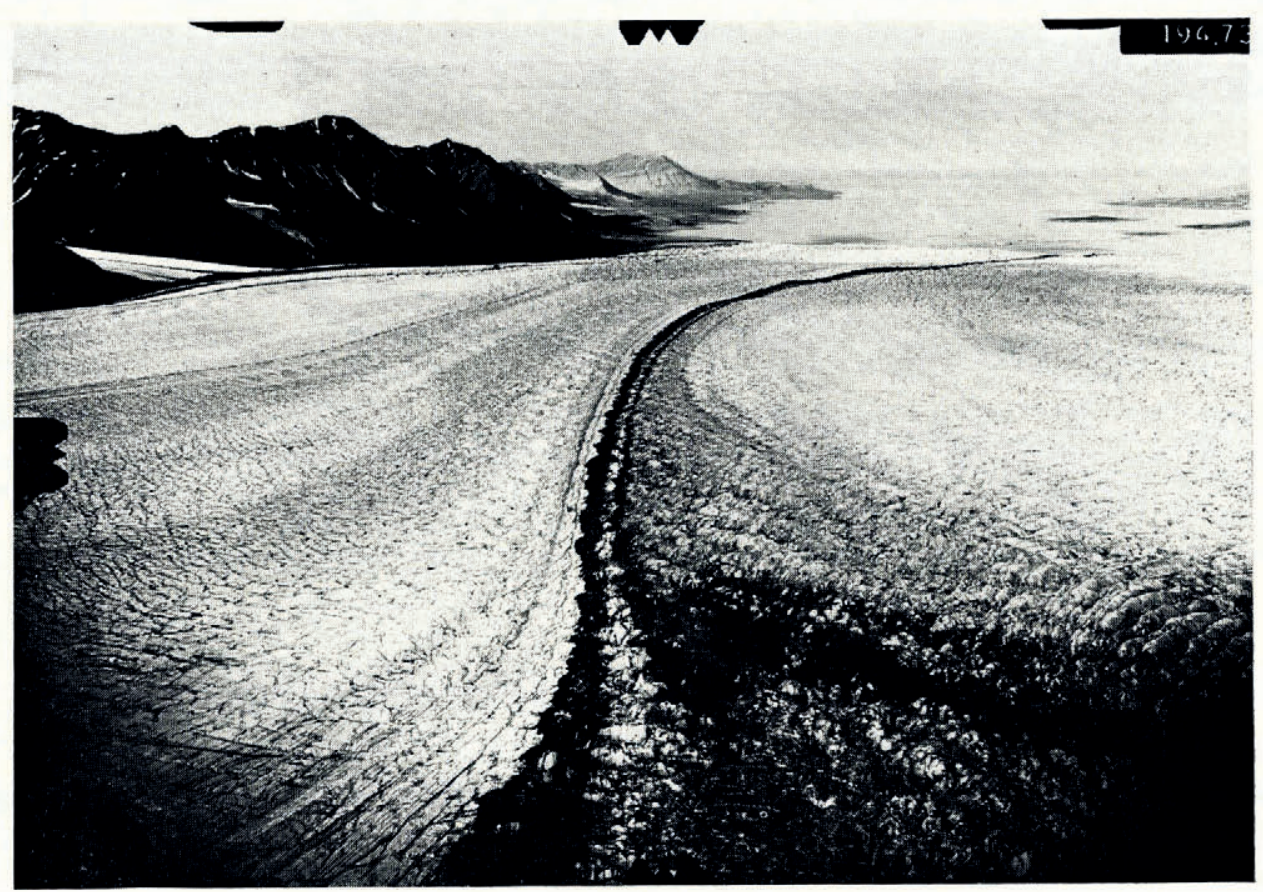

Fig. 5. Photogrammetric view parallel to the direction of flow down Kongsvegen

may be compensated in a period of about ten years so as to reach the state of r 936 if the conditions remain the same.

A comparison of Figures $4 \mathrm{c}$ and $4 \mathrm{~d}$ shows that along the first half of the medial moraine the lateral displacement from 28 July to I August, I 964 exceeds that of the period of 20-28 August 1964. This result can be expected as the ratio of the absolute velocities is I 5 to I. The same applies to the main transverse profile (Fig. 4a). In the play of forces of the glacier branches, the impulse transmitted from Kronebreen laterally to Kongsvegen is predominant at present so that the greatest velocities near the front occur to the left of the medial moraine.

The small amount of the deviation of the direction values indicates that the irregular movements of the seracs relative to each other are compensated in as little as four days.

\section{ACKNOWLEDGEMEnTs}

Grateful acknowledgement is made to all the members of the Deutsche Spitzbergen Expedition $1964 / 65$ for their co-operation and, especially, to Frau Dipl.-Ing. I. Militzer for her careful photogrammetric evaluation work. Dr. J. W. Glen kindly revised the translation.

\section{MS. received 26 April 1966}

\section{REFERENCES}

Finsterwalder, R. 1931. Geschwindigkeitsmessungen an Gletschern mittels Photogrammetrie. Zeitschrift für Gletscherícunde, Bd. I9, Ht. 4-5, p. $25^{1-62}$.

Knizhnikov, Yu. F. 1962. Obshchaya formula dlya opredeleniya poverkhnostnoy skorosti dvizheniya l'da sposobom psevdoparallaksov [A general formula for the determination of the surface velocity of movement of ice by the method of pseudo-parallax]. Izvestiya Vysshikh Uchebnykh Zavedeniy. Geodeziya i Aerofstos"yemka [Neres of Higher Educational Institutions. Geodesy and Aerophotography], 1962, Vyp. I, p. 61 -65 . 
Meier, S. I 965 . Terrestrische Photogrammetrie an einem arktischen Gletscher während der Polarnacht. Bildmessung und Luftbildwesen, Jahrg. 33, Ht. 4, p. 1 77-8I.

Rudolph, I., and Töppler, J. Unpublished. Probleme der photogrammetrischen Geschwindigkeitsmessungen.

Stange, L. 1965. Die geodätischen Arbeiten der Deutschen Spitzbergen-Expedition 1964/65. Vermessungstechnik, Jahrg. 13, Ht. 11, p. 410-14.

Voigt, U. 1965. Die Bewegung der Gletscherzunge des Kongsvegen (Kingsbay, Westspitzbergen). Petermanns Geographische Mitteilungen, Jahrg. I09, I Quartalsheft, p. I-8. 